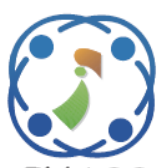

\title{
Cost Optimization of Dynamic Service Reliability: A Case Study of Demand Fulfillment on Enterprise
}

\author{
Mudjahidin Mudjahidin ${ }^{1 *}$ \\ Joko Lianto Buliali \\ Muhammad Nur Yuniarto ${ }^{3}$ \\ ${ }^{1}$ Information System Department, Institut Teknologi Sepuluh Nopember, 60111, Indonesia \\ ${ }^{2}$ Informatics Department, Institut Teknologi Sepuluh Nopember, 60111, Indonesia \\ ${ }^{3}$ Center of Excellence in Automotive and Control System, Institut Teknologi Sepuluh Nopember, 60111, Indonesia \\ * Corresponding author's Email: mudjahidin@is.its.ac.id
}

\begin{abstract}
As a system, private industrial network (PIN) could be computed its service reliability for a specific duration time where the service reliability has two cost components (reliability costs and unreliability cost) which opposite and non-linear. Furthermore, in the PIN, service reliability could have the effect to demand, and the demand also influenced by the external factor. For this reason, we propose a computation of service reliability and find the optimized service time, which can minimize the total reliability cost and unreliability cost for a specific duration time. Furthermore, in this proposed model, reliability and external have the effect to demand. Based on the case study, we implement and simulate the model with random service time, and, as an improvement, we simulate again the model by substitute random service time with optimized service time. The simulation results show the different dynamic value of demand, reliability, average reliability, reliability cost and unreliability cost, where the results from the simulation with optimized service time are mostly better than the simulation with random service time. The total reliability cost of service does not all decrease, but the overall total reliability cost decreases, that is $\$ 3,409,315$ became $\$ 313,595$.
\end{abstract}

Keywords: Service reliability, System dynamics model, Demand, Optimized service time, Reliability cost, Unreliability cost.

\section{Introduction}

System reliability might have two types of cost, namely reliability cost (such as the cost to improve maintenance, the cost to improve quality, the inventory cost of component [1-3]) and unreliability cost (such as the cost of reliability decrease, damage cost, loss sales [4-6]). Commonly, both costs could be non-linear and opposite each other [7, 8]. This condition causes the opportunity cost when the reliability of a system is high, it causes reliability cost increase, and unreliability cost decrease and another hand, if it is low, reliability costs decrease and unreliability cost increase.

Furthermore, in a system, reliability might have a relationship with productivity, effectiveness, awareness, design [9-12]. As well, in a dynamic system, reliability might also have a relationship with efficiency, repair, and the degradation process [13-15].

Based on the costs of system reliability and the reliability relationship in a system as described above, raised an issue that is how to find a value of service time which can minimize the total reliability cost and unreliability cost and how effect reliability to performance or other variables in a system. Related to the optimization of the system reliability, previously, a technique for solving a family of multi-state systems (MSS) reliability optimization problems presented to minimal cost of investment [16]. The study is followed using a multi-processor genetic algorithm in order to solve the structural optimization problem [17] and solving multiple objective multi-state reliability optimization design (maximization of system availability minimization of costs) developed by GA [18]. Algorithm 
Combination of ant colony optimization and strength Pareto fitness assignment procedure to solve both continuous function and combinatorial optimization problems in reliability engineering [19]. Next, GA used to optimize the electrical network reliability [20] and solving multi-objective reliability optimization using particle swarm [21]. Therefore, in this article, we propose a computation of service reliability and find the optimized service time, which can minimize the total reliability cost and unreliability cost for a specific duration time. Furthermore, in this proposed model, reliability and external have the effect to demand.

For the purpose, we develop a system dynamics model which consists of many variables forming the feedback to accommodate the reliability effect to demand. In the model, the demand variable also affected by the external factor. In this article, the name given to the model is cost optimization of dynamically service reliability (CODSR).

To prove that the model can be used to solve the issue mentioned, in this article, we implement CODSR model on the case study of the enterprise which has IT product demand, IT service demand, and warranty demand for both (as a mandatory after delivery of the product and service). In this implementation, we simulate CODSR model with two scenarios. The first, simulation use the service time generating by the exponential number generator, and the second, as an improvement scenario, simulation use the fixed service time resulting from the optimization value of reliability cost and unreliability cost. Next, at the end of this article, we compare and analyze the result of the two scenarios.

We organize the remainder article as follows. Section 2 presents the model of cost optimization of dynamically service reliability that consists of reliability and average reliability of dynamic service (2.1), cost of reliability and unreliability (2.2), and cost optimization method (2.3). Section 3 provides the case study that consists of the CODSR model implementation (3.1), model testing (Section 3.2), and scenario simulation (3.3). Section 4 presents the result that consists of scenario simulation 1 (4.1), cost optimization (4.2), and scenario simulation 2 (4.3). Finally, the conclusion is presented in section 6.

\section{Cost optimization of dynamically service reliability}

In this section, we present CODSR as a system dynamics model that can be used to compute the

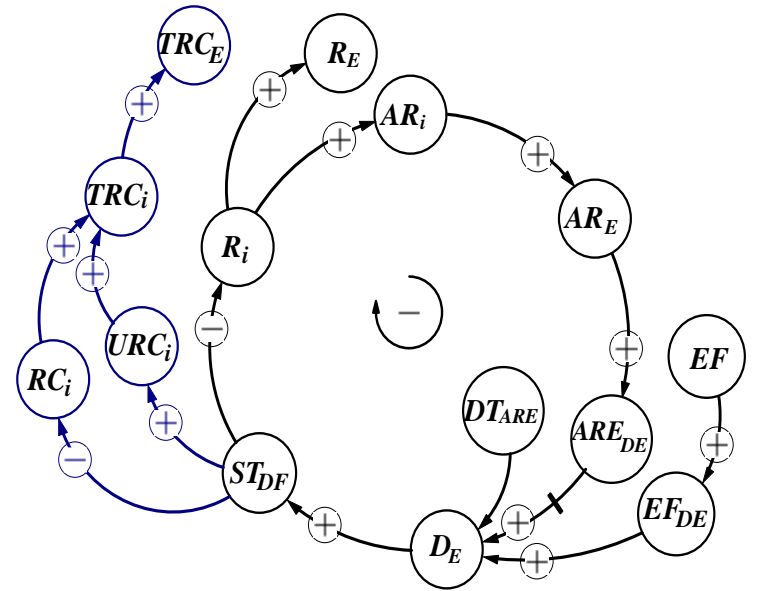

Figure. 1 CLD of CODSR model with the external factor $(E F)$ and average reliability effect $\left(A R E_{D E}\right)$ to demand

$\left(D_{E}\right)$

dynamic service reliability and find the optimized value of total reliability cost consisting of reliability cost and unreliability cost on a causal loop diagram (CLD) as shown in Fig. 1. The CODSR model that we proposed is the causal loop diagram divided into two parts. The first part of the model (black line) is used to compute the reliability and average reliability of dynamic service in an enterprise. In this model, the demand is affected by the external factor. Next, the second part of the model (blue line) is used to compute the total reliability cost for individual service and all service. Therefore, in the next section, we describe how to compute each variable in two parts of CODSR model.

\subsection{Reliability and average reliability of dynamic service}

Based on the first part of Fig. 1 (black line), the reliability and average reliability of dynamic service in the first part of CODSR model form feedback with the negative loop beginning at the demands of enterprise $\left(D_{E}\right) . D_{E}$ consists of several demands, where the amount of each demand resulted by a specific distribution or a fixed value. Each demand has dimensions of service reliability that set by an enterprise $\left(D S R_{E}\right) . D_{E}$ is affected by the external factor $(E F)$ through the value effect of an external factor against it $\left(E F_{D E}\right)$ as studied by [22-25] that resulted by a lookup function. $E F$ has a value between 0 to 1 depending on the external factor condition (such as economic condition, the power of competition, and the effect of technological development). Next, $E F_{D E}$ is a value resulting from the lookup function caused by $E F$.

Firstly, we consider $E F$ and $E F_{D E}$ as $x_{i}$ and $y_{i}$, respectively. The equation of $E F$ and $E F_{D E}$ as $x_{i}$ and $y_{i}$ is described as follows. 


$$
\begin{gathered}
y_{i}\left(x_{i} ; 0 \leq x_{i} \leq 1\right)= \\
\left\{\begin{array}{c}
0, \text { if } 0 \leq E F \leq x_{1} \\
y_{1}, \text { if } x_{1}<E F \leq x_{2} \\
y_{2}, \text { if } x_{2}<E F \leq x_{3} \\
\cdot \\
\cdot \\
y_{n}, \text { if } x_{n}<E F \leq x_{n+1}
\end{array}\right.
\end{gathered}
$$

Where, if $D_{E}>0$ then service time of demand fulfilment $\left(S T_{D F}\right)$ is generated by a random number of current distribution or a fixed time. The random number of $S T_{D F}$ that used to compute CODSR could have Exponential, Poisson, Gamma, or Weibull distribution as described by [9, 26, 27].

We compute the reliability of individual service based on $D S R_{E}\left(R_{i}\right)$ which has specific reliability distribution function $f(x)$ with service time of demand fulfillment for each reliability dimension $\left(S T_{D F}\right)$ using equation as follows.

$$
R_{i}=f(x)
$$

Next, we compute the reliability of all services $\left(R_{E}\right)$ as the parallel arrangement of $R_{i}$ using equation as follows.

$$
R_{E}=1-\prod\left(1-R_{i}\right)
$$

Furthermore, in CODSR, we compute the average reliability of individual service $\left(A R_{i}\right)$ every interval time for computing average reliability $\left(I T_{A R}\right)$ using equation as follows.

$$
A R_{i}=\frac{A_{R}}{N_{R}} \text { for every } I T_{A R}
$$

Where, $A_{R}$ and $R_{R}$ are the accumulated reliable $R_{i}$ over a specific interval time and Number of reliable $R_{i}$ over one specific of interval time, respectively. Next, the average reliability of all services $\left(A R_{E}\right)$ computed using equation as follows.

$$
A R_{E}=\frac{A A R_{I}}{N_{A R}} \text { for every } I T_{A R}
$$

Where, $A A R_{I}$ and $N_{A R}$ are the accumulated of capable $A R_{i}$ over a specific of interval time and the number of capable $A R_{i}$ over a specific of interval time, respectively.

$A R_{E}$ affect $D_{E}$ through the value of average reliability effects against it $\left(A R E_{D E}\right)$ so that CODSR model forms a feedback loop. $A R E_{D E}$ is a value resulted from the lookup function caused by $A R_{E}$ (Eq. (5)) with the delay time of $A R E_{D E}\left(D T_{A R E}\right)$. As a lookup function, we consider $A R_{E}$ as $x_{i}$ that have a value between 0 and 1 , and $A R E_{D E}$ as $y_{i}$ [28]. Therefore, this lookup function described as follows.

$$
=\left\{\begin{array}{c}
y_{D_{i}}\left(x_{i} ; 0 \leq x_{i} \leq 1\right) \\
0, \text { if } 0 \leq A R_{E} \leq x_{1} \\
y_{1}, \text { if } x_{1}<A R_{E} \leq x_{2} \\
y_{2}, \text { if } x_{2}<A R_{E} \leq x_{3} \\
\cdot \\
\cdot \\
y_{n}, \text { if } x_{n}<A R_{E} \leq x_{n+1}
\end{array}\right.
$$

All relationship among variables in the first part of CODSR model (see Fig. 1) is positive (+), except the ties between, $S T_{D F}$ and $R_{i}$ are negative (-). Hence, the relationship among variables in the first part of CODSR model has the negative feedback, where the relationship of among variables in system dynamics model is studied by [29-33].

\subsection{Cost of reliability and unreliability}

In the second part of Fig. 1, the reliability cost of each $D S R_{E}\left(R C_{i}\right)$ and the unreliability cost of each $D S R_{E}\left(U R C_{i}\right)$ presented in the second part of CODSR model (see Fig. 1 with blue line). Where, $R C_{i}$ and $U R C_{i}$ are depending on $S T_{D F}[7,8,34,45]$ and resulted from the lookup function. Next, $S T_{D F}$ considered as $x_{i}$, and $R C_{I}$ and $U R C_{I}$ are regarded as $y_{i}$. So, the lookup functions are computed as follows.

$$
\begin{gathered}
\quad \\
y_{i}\left(x_{i} ; \min S T_{D F} \leq x_{i} \leq \max S T_{D F}\right) \\
\left\{\begin{array}{c}
y_{1}, \text { if } x_{1} \leq S T_{D F} \leq x_{2} \\
y_{2}, \text { if } x_{2} \leq S T_{D F} \leq x_{3} \\
\cdot \\
\cdot \\
y_{n}, \text { if } x_{n} \leq S T_{i} \leq x_{n+1}
\end{array}\right.
\end{gathered}
$$

As a note, based on Eqs. (2) and (7), if $S T_{D F}$ decreases, it causes $R_{i}$ and $R C_{i}$ to become the increase but $U R C_{I}$ decrease.

Next, the computation of total reliability cost of each $D S R_{E}\left(T R C_{i}\right)$ and total reliability cost of all $D S R_{E}\left(T R C_{E}\right)$ respectively are presented as follows.

$$
\begin{aligned}
& T R C_{i}=R C_{I}+U R C_{I} \\
& T R C_{E}=\sum T R C_{I}
\end{aligned}
$$

\subsection{Cost optimization method}

After presenting CODSR model (in section 2.1 and 2.2), to achieve the minimal value of $T R C_{i}$ and $T R C_{E}$, in this section, we propose three steps on CODSR model that described as follows. 
Table 1. The demands of enterprise

\begin{tabular}{|c|c|c|}
\hline Demand & $\begin{array}{c}\text { Compo } \\
\text { nent }\end{array}$ & Description \\
\hline \multirow[t]{3}{*}{$D_{P}$} & $D D_{P 1}$ & $\begin{array}{l}\text { Randomized number of the } \\
\text { uniform distribution, minimum } \\
\text { value }=0 \text { and maximal value }= \\
E F_{D E}(1,2,3 \text {, or } 4)(\text { Eq. (1)) }\end{array}$ \\
\hline & $D D_{P 2}$ & $\begin{array}{l}1 \text { if at } D T_{D S}=15 \text { days, } D D_{S 1}> \\
0\end{array}$ \\
\hline & $D D_{P 3}$ & $\begin{array}{l}A R E_{D E} \text { with } D T_{A R E}=30 \text { days } \\
\text { (Based on Eq. (6)) }\end{array}$ \\
\hline \multirow[t]{3}{*}{$\overline{D_{S}}$} & $D D_{S 1}$ & $\begin{array}{l}\text { Randomized number of thr } \\
\text { uniform distribution, minimum } \\
\text { value }=0 \text { and maximal value }= \\
E F_{D E}(1,2 \text {, or } 3 \text { ) (Eq. (1)) }\end{array}$ \\
\hline & $D D_{S 2}$ & $\begin{array}{l}1 \text { if at } D T_{D P}=15 \text { days, } D D_{P 1}> \\
0\end{array}$ \\
\hline & $D D_{S 3}$ & $A R E_{D E}$ with $D T_{A R E}=30$ days \\
\hline \multirow[t]{2}{*}{$D_{W}$} & $D_{P W}$ & $D_{P}$ after $D T_{P W}=10$ days \\
\hline & $D_{S W}$ & $D_{S}$ after $D T_{S W}=10$ days \\
\hline
\end{tabular}

1. In the first step, we change $S T_{D F}$ into the increasing variable linearly, from minimal $S T_{D F}$ at $T=0$ to maximal $S T_{D F}$ at last time of simulation with a Gradient value increase $S T_{D F}\left(G_{S T}\right)$ that computed with as follows.

$$
G_{S T}=\frac{\max S T_{D F}-\min S T_{D F}}{\mathrm{t}}
$$

2. Next, in the second step, we compute $R_{i}$ based on $S T_{D F}=0$ at $T=0$ to maximal $S T_{D F}$ at last time of simulation with a gradient value by $G_{S T}$ with Eq. (2), where $S T_{D F}$ is time variable in $f(x)$ that increase linearly.

3. Finally, in CODSR model presented, we get $S T_{D F O}$ as the optimal value of $S T_{D F}$ based on the minimum $T R C_{i}$ that computed by using Eq. (8). Next, $S T_{D F O}$ is the fixed value of service time that used to compute the reliability and its costs.

\section{Case study}

To prove the CODSR model presented can be used to obtain the optimal value of dynamically service reliability $\left(T R C_{i}\right.$ and $\left.T R C_{E}\right)$, then we implement this model on a case study of the enterprise which has especially $D_{E}$. In this case study, $D_{E}$ consists of IT product $\left(D_{P}\right)$, IT service $\left(D_{S}\right)$, and warranty of both as mandatory to guaranty to product and service have delivered to customers $\left(D_{W}\right)$. Therefore $D_{E}$ is shown in Table 1 .

$D_{P}$ has two $D S R_{E}$, that is product delivery as the first service reliability dimension $(P D)$ and product installation as the second service reliability dimension $(P I)$ while each $D_{S}, D_{P W}$, and $D_{S W}$ has one $D S R_{E}$, that is service completion $(S C)$, product warranty $(P W)$ and service warranty $(S W)$, respectively as a service reliability dimension. Next, if $D_{p}, D_{S}, D_{P W}$ and $D_{S W}>0$ then $S T_{D F}$ of each $D S R_{E}$ is generated by the randomized number of an Exponential distribution with the parameters $\min S T_{D F}$, $\max S T_{D F}$, the average of $S T_{D F}\left(\mu_{S T D F}\right)$, and deviation standard of $S T_{D F}\left(\sigma_{S T D F}\right)$ for each $D S R_{E}$.

It is related to the data requirements of the case study, $S T_{D F}$ of the case study presented in Table 2. The lookup function of $E F$ (Eq. (1)) as an external factor affect the composition of IT product and service demand $\left(D_{P 1}\right.$ and $\left.D_{S 1}\right)$ and $A R_{E}$ (Eq. (6)) as average reliability of all services affect to the component of IT product and service demand $\left(D_{P 3}\right.$ and $\left.D_{S 3}\right)$ are shown in Fig. 2. Next, the lookup function of $R C_{i}$ and $U R C_{i}$ (Eq. (7)) shown in Fig. 3. These data, we have collected from the enterprise that provides IT products and services to meet the customers' need, where the values in this table result from the parameters of data testing.

\subsection{Implementation of CODSR}

Implementation CODSR model to the case study has the characteristic as a system dynamics that are containing feedback, time delay, and non-linearly $[29,30,36,37]$. Therefore, implementation of CODSR model uses the system dynamics simulation by converting CLD (see Fig. 1) into a structure of stock flow diagram (SFD) as shown in Fig. 4.

\subsection{Model testing}

The developed SFD is tested by structural test to find out whether the model has formed a system dynamics model and have the units appropriately. The structural testing shows SFD is the closed system, no terminate variable and containing the negative feedback that is caused by the relationship between $S T_{D F}$ and $R_{i}$. In this SFD, the closed system achieved by adding accumulation of $A R_{E}$ $\left(A A R_{E}\right)$, accumulated of $A R_{E}\left(A c R_{E}\right)$, and accumulation of $T R C_{E}\left(A T R C_{E}\right)$ as the stock variables in SFD of CODSR. Next, as the stock variable in SFD, after $A A R_{E}, A c R_{E}$ and $A T R C_{E}$ must add the outflow variables, that are the outflow of average reliability on enterprise $\left(O A R_{E}\right)$, outflow of reliability on enterprise $\left(O R_{E}\right)$, and total reliability cost of enterprise $\left(O T R C_{E}\right)$ (see Fig. 4). In this CODSR model, $D_{E}$ has product/day as a unit for $D_{P}$ and $D_{P W}$ and service/day for as a unit for $D_{S}$ and $D_{S W}$. Next, $T R C_{i}$ and $T R C_{E}$ have the 
dollar as a unit, while $R_{i}$, and $A R_{i}$ are dimensionless (dmnl).

\subsection{Scenario simulation}

To simulate the case study implemented on CODSR model, we use two scenarios. Scenario 1 is the simulation of CODSR model using $S T_{D F}$ that generated by an exponential number generator (see Table 2). While scenario 2, as an improvement, is the optimization scenario that simulates CODSR model using $S T_{D F O}$.

However, before simulating the Scenario 2, we must find the optimized value of each $D S R_{E}$ $\left(T R C_{i O}\right)$ and the optimized value of each $D S R_{E}\left(T R C_{E O}\right)$. The optimized values is resulted from the addition of reliability cost and unreliability cost by following the steps of the cost optimization method (Section 3.3). For this work, we simulate the CODSR model on the case study with both scenario during simulation time $T=0$ to $T=100$ day.

\section{Result}

In this section, the results of scenario simulation 1 and 2 presented in section 5.1 and 5.3. While the results of the optimization value of $T R C_{i}$ presented in section 5.2.

\subsection{Result of scenario simulation 1}

The results of scenario simulation 1 shown in Fig. 5 in the form of the dynamic behaviour of demands, reliabilities, average reliabilities, and total reliability costs, which each are for $D S R_{E}=$ $P D, P I, S C, P W$, and $S W$. The demands consist of $D_{P}, D_{P W}, D_{S}$, and $D_{S W}$ that occur dynamically at $T=0$ to $T=100$ day (Fig. 5 (a)). In this result, when there is no demand, then reliability is 0 . The reliability of individual service is dimensionless having a value minimal 0 and maximum 1 (Eq. (2)) (Fig. 5 (b)).
In this reliability values, $R_{E}$ is always bigger than each $R_{i}$ for $i=P D, P I, S C, P W$, and $S W$ (Eqs. (2) and (3)). Based on Eq. (3), if at $T=t, R_{E}=0$ that means all $R_{i}=0$ at the time. Next, $A R_{i}$ occurs every for interval time for computation of average reliability $\left(I T_{A R}\right)$ (Fig. 5 (c)) having a value minimal 0 and maximum 1 (Eq. (4)). In this average reliability values, different from $R_{E}, A R_{E}$ can be smaller than $A R_{i}$ for $i=P D, P I, S C, P W$, and $S W$ (Eqs. (4) and (5). If every $I T_{A R}, A R_{E}=0$ that means all $A R_{i}=0$ at the same time.

Table 2. Parameter of exponential distributions of service time

\begin{tabular}{|c|c|}
\hline Parameter & Value (unit) \\
\hline $\begin{array}{ll}S T_{P D_{\min }} & S T_{P D_{\max }}, \mu_{S T_{P D^{\prime}}} \\
\text { and } \sigma_{S T_{P D}} & \\
\end{array}$ & $\begin{array}{l}1.75,3.78,2.21 \text {, and } \\
0.5 \text { (day) }\end{array}$ \\
\hline $\begin{array}{l}S T_{P I_{\text {min }}}, S T_{P I_{\text {max }}}, \mu_{S T_{P I}}, \text { and } \\
\sigma_{S T_{P I}}\end{array}$ & $\begin{array}{l}0.6,0.96,0.702, \text { and } \\
0.1 \text { (day) }\end{array}$ \\
\hline $\begin{array}{l}S T_{S C_{\text {min }}}, S T_{S C_{\text {max }}}, \mu_{S T_{S C}}, \text { and } \\
\sigma_{S T_{S C}}\end{array}$ & $\begin{array}{l}2.76,6.92,4.29 \text {, and } \\
1.5 \text { (day) }\end{array}$ \\
\hline $\begin{array}{l}S T_{P W_{\text {min }}}, S T_{P W_{\text {max }}}, \mu_{S T_{P W}}, \\
\text { and } \sigma_{S T_{P W}}\end{array}$ & $\begin{array}{l}0.55, \quad 0.94, \quad 0.651, \\
\text { and } 0.1 \text { (day) }\end{array}$ \\
\hline $\begin{array}{l}S T_{S W_{\text {min }}}, S T_{S W_{\text {max }}}, \mu_{S T_{S W}}, \text { an } \\
\mathrm{d} \sigma_{S T_{S W}}\end{array}$ & $\begin{array}{l}1.25,1.95,1.47 \text {, and } \\
0.3 \text { (day) }\end{array}$ \\
\hline $\begin{array}{l}\mu_{R F_{P D}}, \mu_{R F_{P I}}, \mu_{R F_{S C},} \mu_{R F_{P W}}, \\
\mu_{R F_{S W}}, \text { and } E F\end{array}$ & $\begin{array}{l}2.21, \quad 0.702, \quad 4.29 \\
0.651,1.47 \text { (day), } 0.6\end{array}$ \\
\hline $\begin{array}{l}S T_{P D_{\min }}, S T_{P D_{\max }}, \quad \mu_{S T_{P D}}, \\
\text { and } \sigma_{S T_{P D}}\end{array}$ & $\begin{array}{l}1.75,3.78,2.21 \text {, and } \\
0.5 \text { (day) }\end{array}$ \\
\hline $\begin{array}{l}S T_{P I_{\text {min }}}, S T_{P I_{\text {max }}}, \mu_{S T_{P I}}, \text { and } \\
\sigma_{S T_{P I}}\end{array}$ & $\begin{array}{l}0.6,0.96,0.702 \text {, and } \\
0.1 \text { (day) }\end{array}$ \\
\hline $\begin{array}{l}S T_{S C_{\text {min }}}, S T_{S C_{\text {max }}}, \mu_{S T_{S C}} \text {, and } \\
\sigma_{S T_{S C}}\end{array}$ & $\begin{array}{l}2.76,6.92,4.29 \text {, and } \\
1.5 \text { (day) }\end{array}$ \\
\hline $\begin{array}{l}S T_{P W_{\text {min }}}, S T_{P W_{\text {max }}}, \mu_{S T_{P W}}, \\
\text { and } \sigma_{S T_{P W}}\end{array}$ & $\begin{array}{l}0.55,0.94, \quad 0.651, \\
\text { and } 0.1 \text { (day) }\end{array}$ \\
\hline $\begin{array}{l}S T_{S W_{\text {min }}}, S T_{S W_{\text {max }}}, \mu_{S T_{S W^{\prime}}} \\
\text { and } \sigma_{S T_{S W}}\end{array}$ & $\begin{array}{l}1.25,1.95,1.47 \text {, and } \\
0.3 \text { (day) }\end{array}$ \\
\hline $\begin{array}{l}\mu_{R F_{P D}}, \mu_{R F_{P I}}, \mu_{R F_{S C}}, \mu_{R F_{P W}}, \\
\mu_{R F_{S W}}, \text { and } E F\end{array}$ & $\begin{array}{l}2.21, \quad 0.702, \quad 4.29 \\
0.651,1.47 \text { (day), } 0.6\end{array}$ \\
\hline
\end{tabular}

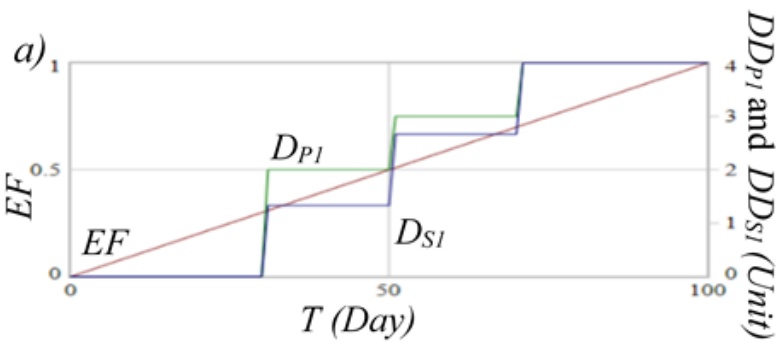

(a)

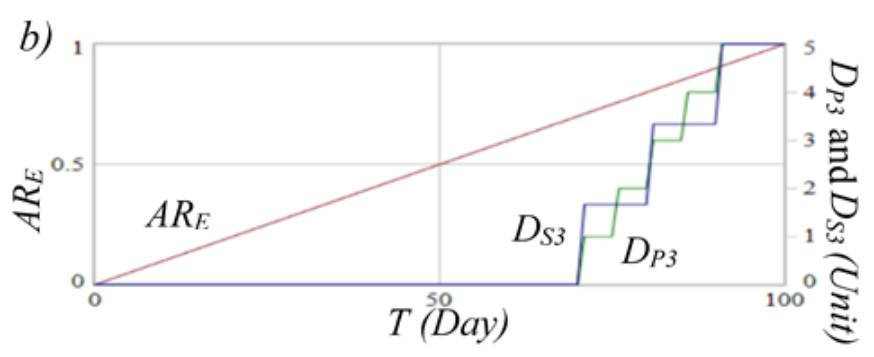

(b)

Figure 2. (a) The value of external factor $(E F)$ affect to the demands $\left(D D_{P 1}\right.$ and $\left.D D_{S 1}\right)$ and (b) The value of average reliability affect $\left(A R_{E}\right)$ to the demands $\left(D_{P 3}\right.$ and $\left.D_{S 3}\right)$ 
a)

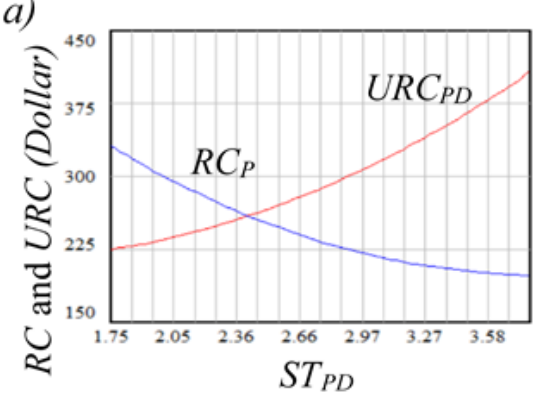

(a)

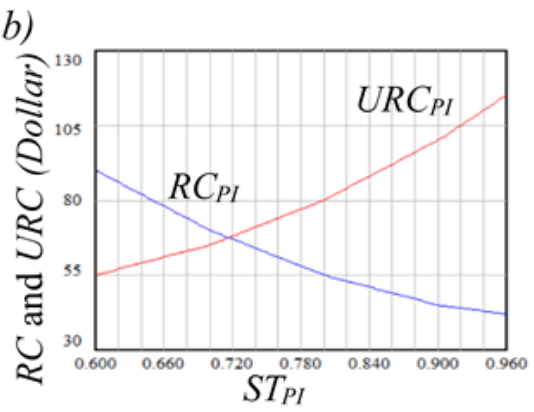

(b)

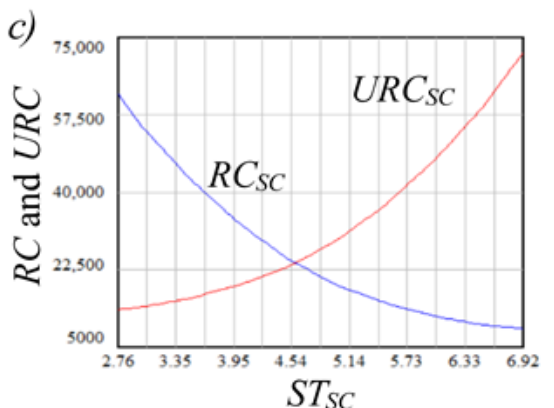

(c)

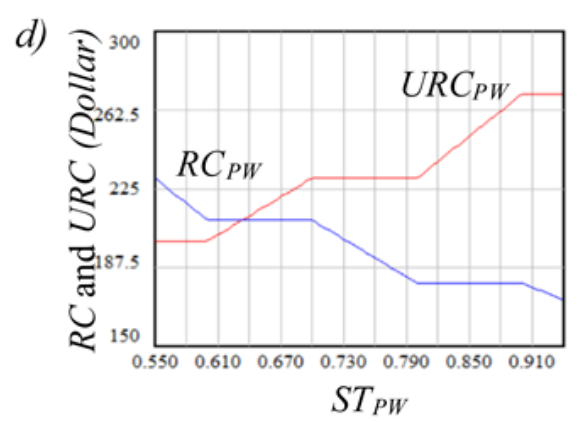

(d)

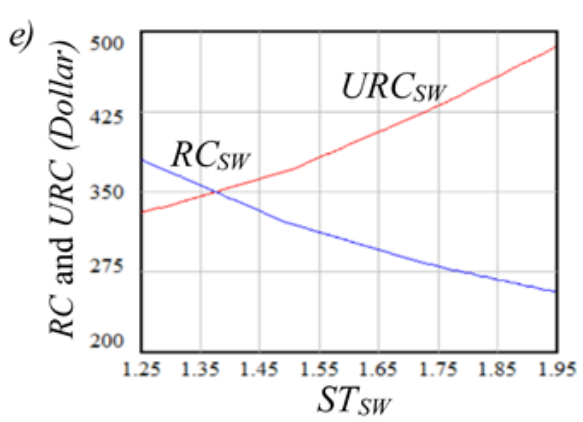

(e)

Figure. 3 Reliability cost and unreliability cost as the values are resulted from lookup function based on service time: (a) product deliver, (b) product installation, (c) service completion, (d) product warranty, and (e) service warranty

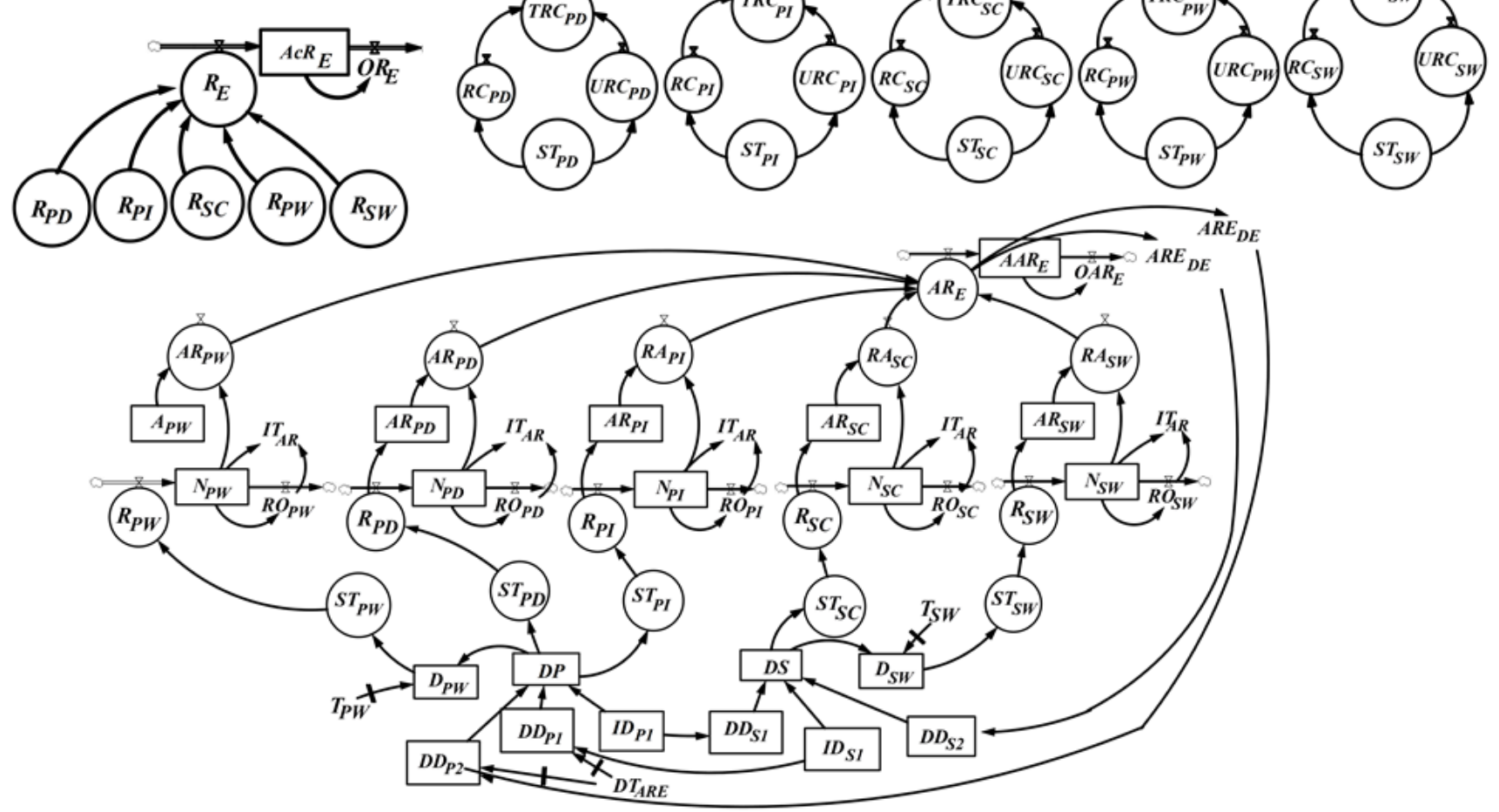

Figure. 4 SFD of CODSR implemented to the case study 


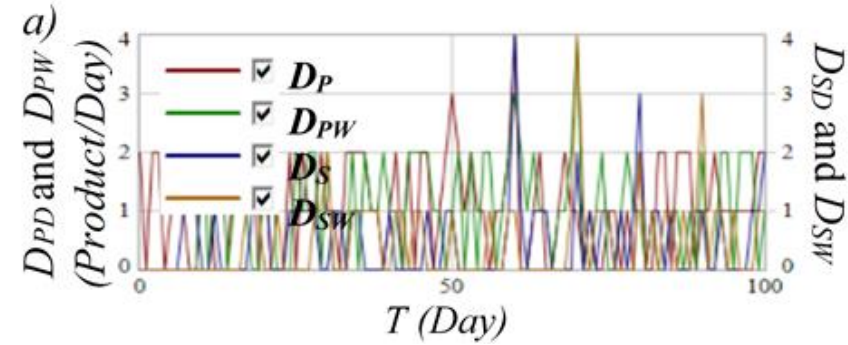

(a)

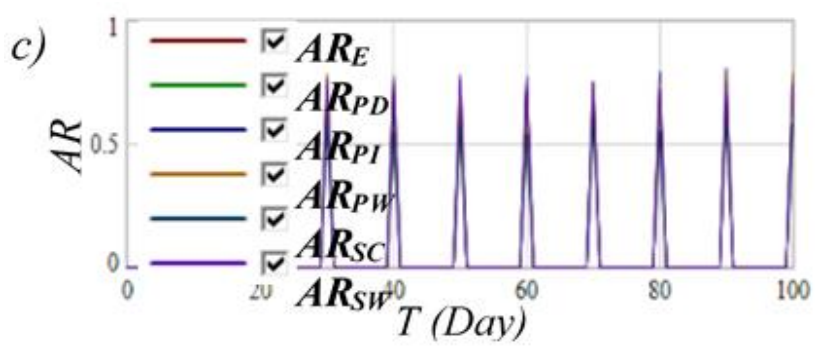

(c)

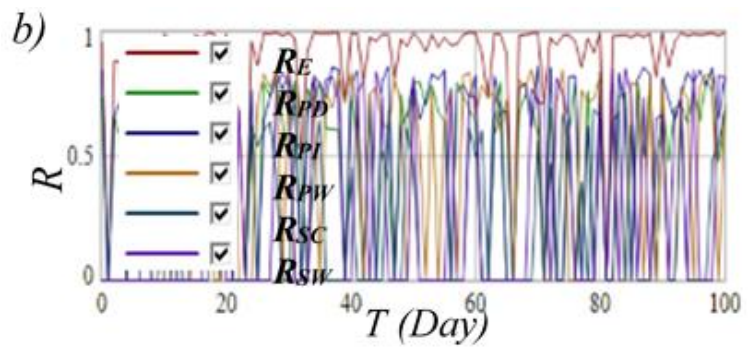

(b)

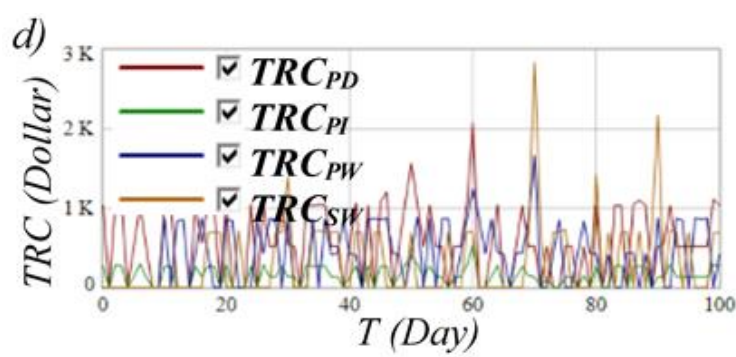

(d)

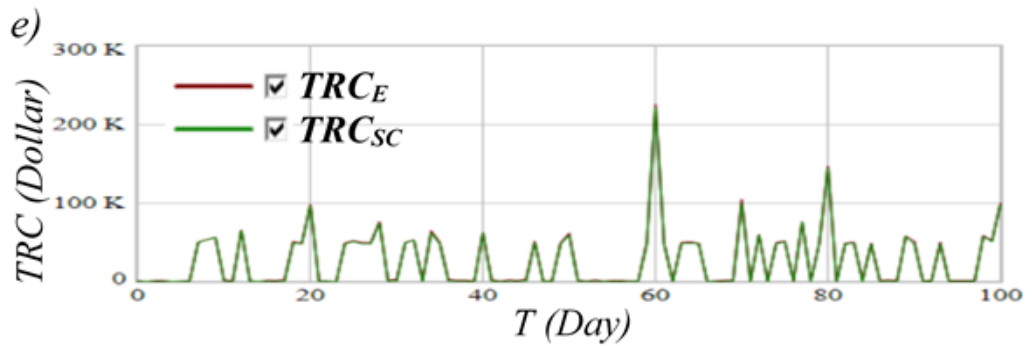

(e)

Figure. 5 Results of scenario simulation 1 in the form of dynamic behavior of: (a) Demands, (b) Reliabilities, (c) Average reliabilities, (d) Total reliability costs of PD, PI, PW, and SC, (e) Total reliability costs of PD and E

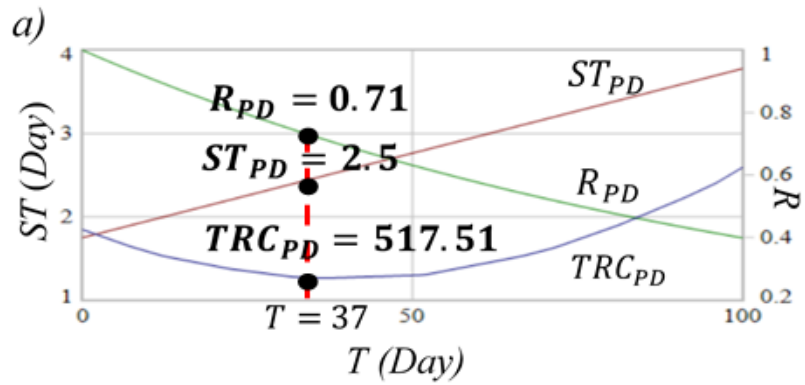

(a)

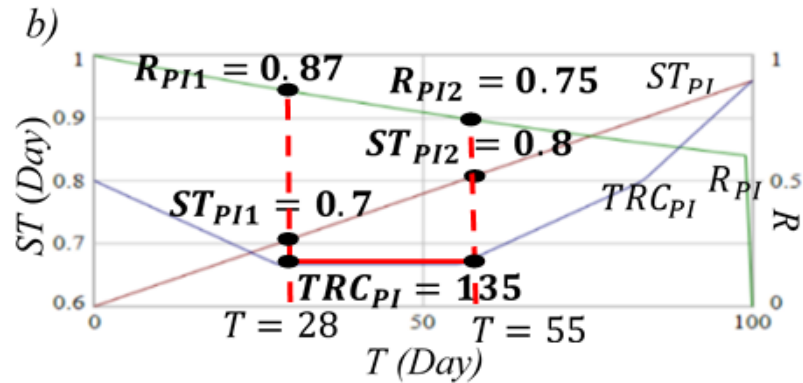

(b)

Figure 6. Optimal value of service time result the minimum total of: (a) $T R C_{P D}$ and (b) $T R C_{P I}$

Next, $T R C_{i}$ separated in Fig. 5 (d) for $T R C_{P D}, T R C_{P I}$, and $T R C_{P W}$, and $T R C_{S W}$ ) and Fig. 5 (e) (for $T R C_{S C}$ and $T R C_{E}$ ) (Eqs. (8) and (9)). This separation is done because there is a big difference between the two groups of total reliability cost (see Fig. 3).

\subsection{Result of cost optimization}

After simulation with Scenario 1, the results cost optimization method in this case study presented as follows.
- Step 1: $G_{S T}$ for $D S R_{E}$ for $P D, P I, S C, P W$ and $S W$ are 0.0203 , $0.0036, \quad 0.0416, \quad 0.0039, \quad$ and 0.007 respectively (use Eq. (7)).

Step 2 and 3: These steps result in $R_{i}$ and the optimal value of $S T_{D F}\left(S T_{D F O}\right)$ that provide the minimal of $T R C_{i}$ for $D S R_{E}=$ $P D, P I, S C, P W$ and $S W$. Therefore, as evidence, Fig. 6 especially show how $R_{i}, S T_{D F O}$, and $T R C_{i}$ for $P I$ and $P D$ resulted by these steps. Next, all result of these steps summarized in Table 3. 
Table 3. Optimized value of $S T_{I O}, R_{I}$ that result $T R C_{I O}$

\begin{tabular}{|l|r|r|r|r|}
\hline \multicolumn{1}{|c|}{$\boldsymbol{D S} \boldsymbol{R}_{\boldsymbol{E}}$} & \multicolumn{1}{c|}{$\boldsymbol{T}$} & \multicolumn{1}{c|}{$\boldsymbol{R}_{\boldsymbol{i}}$} & \multicolumn{1}{c|}{$\boldsymbol{R}_{\boldsymbol{i}}$} & \multicolumn{1}{c|}{$\boldsymbol{S T}_{\boldsymbol{D} \boldsymbol{D} \boldsymbol{O}}$} \\
\hline$P D$ & 37 & 517.51 & 0.71 & 2.5 \\
\hline$P I$ & 28 to 55 & 135 & 0.87 to 0.75 & 0.7 to 0.8 \\
\hline$S C$ & 42 to 53 & 4800 & 0.67 to 0.6 & 4.51 to 4.96 \\
\hline$P W$ & 64 & 410.12 & 0.68 & 0.8 \\
\hline$S W$ & 35 & 690.16 & 0.84 & 1.5 \\
\hline
\end{tabular}

a)

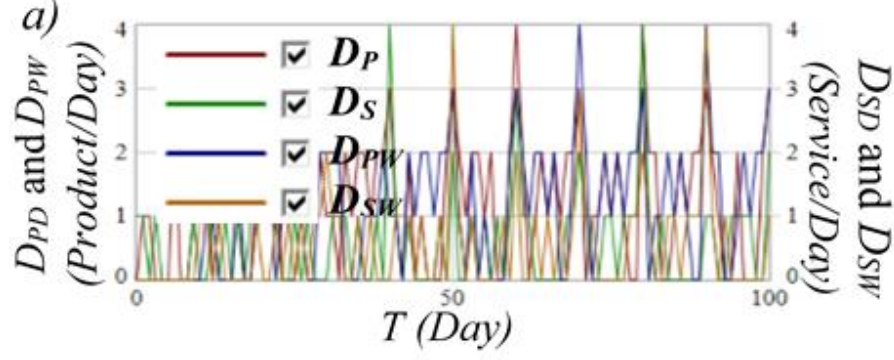

(a)

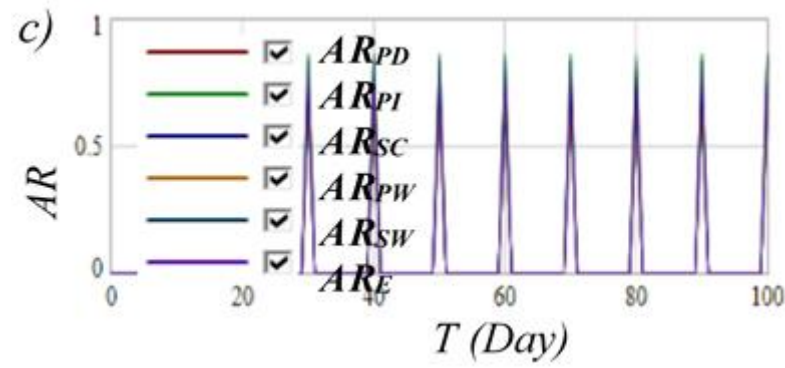

(c)

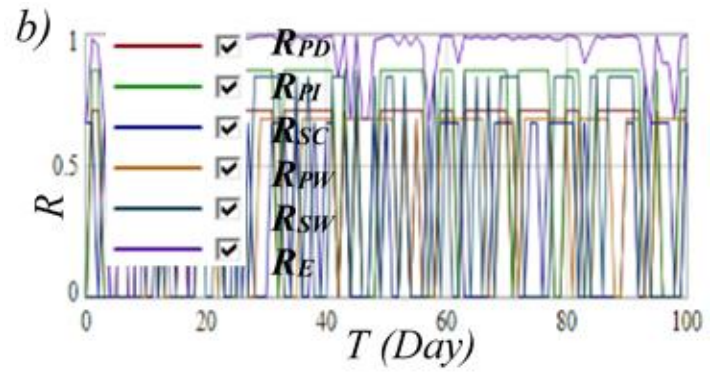

(b)

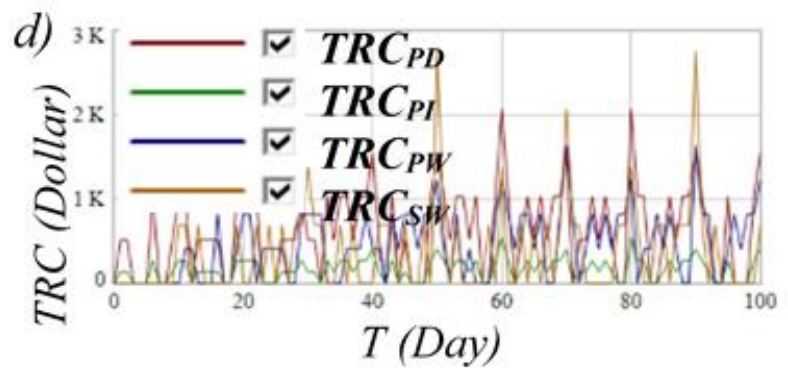

(d)

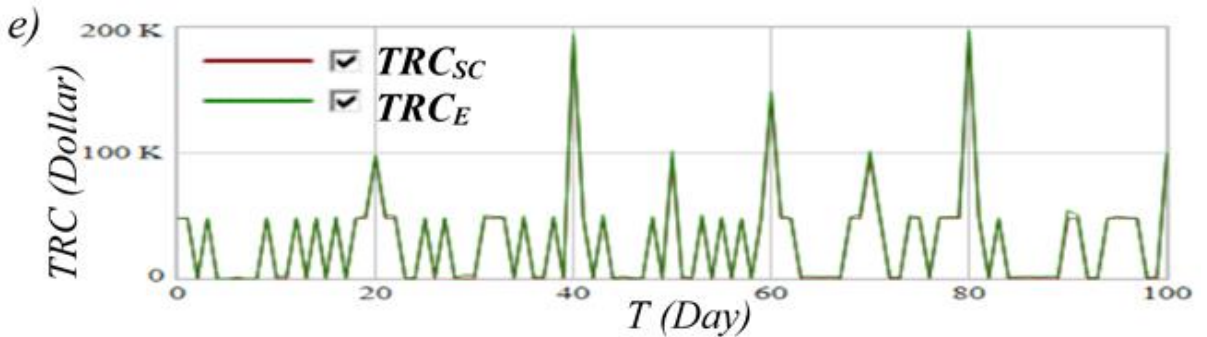

(e)

Figure 7. Results of scenario simulation 2 in the form of dynamic behavior of: (a) demands, (b) reliabilities, (c) average reliabilities, and (d) Total reliability costs for $D S R_{E}=P D, P I, P W$, and $S W$, and (e) $D S R_{E}$ and $T R C_{C S}$

\subsection{Result of scenario simulation 2}

While the results of scenario simulation 2 (the improvement scenario) are shown in Fig. 7. In this scenario, the total of $D_{P}$ and $D_{P W}$ increase, but total $D_{S}$ and $D_{S W}$ decrease during simulation time (Fig. 7 (a)). Next, the increasing of $D_{P}$ and $D_{P W}$ is followed by $R_{P D}, R_{P I}$, and $R_{P W}$ and the decreasing of $D_{S}$ and $D_{S W}$ followed by $R_{S C}$ and $R_{S W}$. Each $R_{i}$ in this scenario is constant (Fig. 7 (b)). Same as scenario simulation 1 , in this scenario, $R_{E}$ is always bigger than each $R_{i}$ for $i=$ $P D, P I, S C, P W$, and $S W$.
In this result, the average reliability of the individual service also has fixed value and equal with the reliability of individual service $\left(A R_{i}=R_{i}\right.$, for $D S R_{E}=P D, P I, S C, P W$, and $\left.S W\right)$. Where, the value of $A R_{i}$ for $D S R_{E}=P D, P I, S C, P W$, and $S W$ is $0.71,0.87,0.67,0.68$, and 0.84 respectively (Fig 7 (c)). It is caused $S T_{D F O}$ for $P I$ and $S C$ that are chosen the minimum $S T_{D F O}(0.7$ and 4.51$)$ so customers will get the faster service time.

Next, for the same reason as Fig 5 (d), the total reliability costs in Fig 7 (d) are separated, that is $T R C_{P D}, T R C_{P I}$, and $T R C_{P W}$, and $T R C_{S W}$. During this simulation time, the total, number of events, the 
Table 4. The results of both Scenario 1 and 2

\begin{tabular}{|c|c|c|c|c|c|c|c|c|c|c|c|}
\hline \multirow{2}{*}{$\begin{array}{c}\text { Varia } \\
\text { ble }\end{array}$} & \multirow{2}{*}{$\begin{array}{l}\text { Sum } \\
\text { mari } \\
\text { ze }\end{array}$} & \multicolumn{2}{|c|}{ Scenario } & \multirow{2}{*}{$\begin{array}{c}\text { Varia } \\
\text { ble }\end{array}$} & \multirow{2}{*}{$\begin{array}{c}\text { Sum } \\
\text { mari } \\
\text { ze }\end{array}$} & \multicolumn{2}{|c|}{ Scenario } & \multirow{2}{*}{$\begin{array}{c}\text { Varia } \\
\text { ble }\end{array}$} & \multirow{2}{*}{$\begin{array}{c}\text { Sum } \\
\text { mari } \\
\text { ze }\end{array}$} & \multicolumn{2}{|c|}{ Scenario } \\
\hline & & 1 & 2 & & & 1 & 2 & & & 1 & 2 \\
\hline \multirow[t]{3}{*}{$D_{P}$} & $\mathrm{~T}$ & 101 & 121 & \multirow[t]{2}{*}{$R_{P W}$} & $\mathrm{~N}$ & 55 & 65 & \multirow[t]{3}{*}{$T R C_{P D}$} & $\mathrm{~T}$ & 53365 & 62619 \\
\hline & $\mathrm{N}$ & 64 & 70 & & $\mathrm{~A}$ & 0.75 & 0.68 & & $\mathrm{~N}$ & 64 & 70 \\
\hline & A & 1.57 & 1.72 & \multirow[t]{2}{*}{$R_{S W}$} & $\mathrm{~N}$ & 52 & 44 & & A & 834 & 895 \\
\hline \multirow[t]{3}{*}{$D_{S}$} & $\mathrm{~T}$ & 63 & 62 & & A & 0.78 & 0.84 & \multirow[t]{3}{*}{$T R C_{P I}$} & $\mathrm{~T}$ & 13928 & 16335 \\
\hline & $\mathrm{N}$ & 58 & 50 & \multirow[t]{2}{*}{$R_{E}$} & $\mathrm{~N}$ & 95 & 96 & & $\mathrm{~N}$ & 64 & 70 \\
\hline & $\mathrm{A}$ & 1.09 & 1.24 & & $\mathrm{~A}$ & 0.94 & 0.95 & & $\bar{A}$ & 218 & 233 \\
\hline \multirow[t]{3}{*}{$D_{P W}$} & $\mathrm{~T}$ & 88 & 111 & \multirow[t]{2}{*}{$A R_{P D}$} & $\mathrm{~N}$ & 10 & 10 & \multirow[t]{3}{*}{$T R C_{S C}$} & $\mathrm{~T}$ & 3265618 & 2976000 \\
\hline & $\mathrm{N}$ & 55 & 65 & & $\mathrm{~A}$ & 0.66 & 0.71 & & $\mathrm{~N}$ & 58 & 50 \\
\hline & $\mathrm{A}$ & 1.6 & 1.7 & \multirow[t]{2}{*}{$A R_{P I}$} & $\mathrm{~N}$ & 10 & 10 & & A & 56304 & 59520 \\
\hline \multirow[t]{3}{*}{$D_{S W}$} & $\mathrm{~T}$ & 55 & 55 & & A & 0.77 & 0.87 & \multirow[t]{3}{*}{$T R C_{P W}$} & $\mathrm{~T}$ & 37840 & 45523 \\
\hline & $\mathrm{N}$ & 52 & 44 & \multirow[t]{2}{*}{$A R_{S C}$} & $\mathrm{~N}$ & 10 & 10 & & $\mathrm{~N}$ & 55 & 65 \\
\hline & $\mathrm{A}$ & 1.06 & 1.25 & & $\mathrm{~A}$ & 0.58 & 0.67 & & $\mathrm{~A}$ & 688 & 700 \\
\hline \multirow[t]{2}{*}{$R_{P D}$} & $\mathrm{~N}$ & 64 & 70 & \multirow[t]{2}{*}{$A R_{P W}$} & $\mathrm{~N}$ & 9 & 9 & \multirow[t]{3}{*}{$T R C_{S W}$} & $\mathrm{~T}$ & 38565 & 37959 \\
\hline & A & 0.65 & 0.71 & & A & 0.75 & 0.68 & & $\mathrm{~N}$ & 52 & 44 \\
\hline \multirow[t]{2}{*}{$R_{P I}$} & $\mathrm{~N}$ & 64 & 70 & \multirow[t]{2}{*}{$A R_{S W}$} & $\mathrm{~N}$ & 9 & 9 & & $\mathrm{~A}$ & 742 & 863 \\
\hline & $\mathrm{A}$ & 0.76 & 0.87 & & A & 0.78 & 0.84 & \multirow[t]{3}{*}{$T R C_{E}$} & $\mathrm{~T}$ & 3409315 & 313595 \\
\hline \multirow[t]{2}{*}{$R_{S C}$} & $\mathrm{~N}$ & 58 & 50 & \multirow[t]{2}{*}{$A R_{E}$} & $\mathrm{~N}$ & 10 & 10 & & $\mathrm{~N}$ & 95 & 96 \\
\hline & $\mathrm{A}$ & 0.58 & 0.67 & & $\mathrm{~A}$ & 0.7 & 0.75 & & $\mathrm{~A}$ & 35888 & 32692 \\
\hline
\end{tabular}

average of $T R C_{S C}$ as well as the total and number of events $T R C_{S W}$ decrease. While the total, number of events, the average of other $T R C_{i}$ increase. As a comparison of the result between Scenario 1 and Scenario 2, the most important factor to note is $T R C_{E}$. Where, in this scenario, $T R C_{E}$ decreases.

For easy comparing, both results of these scenarios summarized in the total value (T), the number of events (N), and the average (A) as shown in Table 4. The summarize of both simulation result show the result of Scenario 2 (scenario simulation use $S T_{D F O}$ ) not all smaller than Scenario 1 (Scenario simulation use the randomized value of $S T_{D F}$ ).

\section{Conclusion}

In this article, we successfully presented CODSR model that can be used to compute dynamic service reliability and proposed the cost optimization method to achieve the optimal value of $T R C_{i}$ and $T R C_{E}$ by optimized service time that can find minimize the total of reliability cost, and unreliability cost.

Next, we implement CODSR model on the case study of demand fulfillment of the enterprise with system dynamics simulation for Scenario 1 to obtain the demand $\left(D_{P}, D_{S}, D_{P W}\right.$, and $\left.D_{S W}\right)$, reliability $\left(R_{i}\right.$ for $i=P D, P I, S C, P W, S W$, and $R_{E}$ average reliability $\left(A R_{i}\right.$ for $i=P D, P I, S C, P W, S W$, and
$A R_{E}$ ) and total of reliability cost dynamically $\left(T R C_{i}\right.$ for $i=P D, P I, S C, P W, S W$, and $\left.T R C_{E}\right)$ during simulation time 100 days. Next, based on the cost optimization method, we simulate CODSR model for scenario 2 as the improvement scenario.

Finally, the results of both simulations show that substitution of the random service time $\left(S T_{D F}\right)$ with the optimized service time $\left(S T_{D F O}\right)$ can cause the increase and decrease in the total reliability cost of individual service $\left(T R C_{i}\right)$ while the overall total reliability cost of all services $\left(T R C_{E}\right)$ is decreased (\$3,409,315 became $\$ 313,595)$. Overall, we can conclude that the result of scenario simulation 2 is better than scenario simulation 1 .

In the future work, as a continuation of this article, we will develop a scenario by changing $T R C_{i}$ $\left(R C_{i}\right.$ and $\left.U R C_{i}\right)$ and simulate to know the change in $S T_{D F}$ and other variables in the model.

\section{Acknowledgments}

We gratefully acknowledge the Ministry for Research, Technology and Higher Education of the Republic of Indonesia. The Ministry was funding and supporting our research at The Doctoral Program in Computer Science, Informatics Department, ITS, under the scheme of BPPDN 2014-2018 and PDD 2018 (Contract No: 
128/SP2H/PTNBH/DRPM/2018 and 787/PKS/ITS/ 2018, 1 February 2018).

\section{References}

[1] J. A. Erkoyuncu, S. Khan, A. L. Eiroa, N. Butler, K. Rushton, and S. Brocklebank, "Perspectives On Trading Cost And Availability For Corrective Maintenance At The Equipment Type Level", Reliability Engineering and System Safety, Vol. 168, pp. 53-69, 2017.

[2] H. Dui, S. Si, and R. C. M. Yam, "A CostBased Integrated Importance Measure Of System Components For Preventive Maintenance", Reliability Engineering and System Safety, Vol. 168, pp. 98-104, 2017.

[3] J. Poppe, R. J. I. Basten, R.N. Boute, and M. R. Lambrecht, "Numerical Study of Inventory Management Under Various Maintenance Policies", Reliability Engineering and System Safety, Vol. 168, pp. 262-273, 2017.

[4] A.G. Bruce, "Reliability Analysis Of Electric Utility SCADA Systems", In: Proc. of the 20th International Conf. on Power Industry Computer Applications, pp. 201-205, 1997.

[5] Y. K. Wen, "Reliability And PerformanceBased Design", Structural Safety, Vol. 23, pp. 407-428, 2001.

[6] R. Scribner, K. P. Theall, B. Ghosh-Dastidar, K. Mason, D. Cohen, and N. Simonsen, "Determinants of Social Capital Indicators At The Neighborhood Level: A Longitudinal Analysis of Loss of off-Sale Alcohol Outlets And Voting", Journal of Studies on Alcohol and Drugs, Vol. 68, No. 6, pp. 934-943, 2007.

[7] C. M. F. Lapa, C, M. N. A. Pereira, and M. P. de Barros, "A Model For Preventive Maintenance Planning By Genetic Algorithms Based In Cost And Reliability," Reliability Engineering and System Safety, vol. 91, p. 233240, 2006.

[8] K. O. Kim, T. Roh, J. -W. Lee, and M. J. Zuo, "Derating Design For Optimizing Reliability And Cost With An Application to Liquid Rocket Engines", Reliability Engineering and System Safety, Vol. 14, pp. 13-20, 2016.

[9] M. Abate, M. Lijesen, E. Pels, and A. Roelevelt, "The Impact Of Reliability on The Productivity of Railroad Companies", Transportation Research Part E: Logistics and Transportation Review, Vol. 51, pp. 41-49, 2013.
[10] F. Kristjanpoller, A. Crespo, L. Barberá, and P. Viveros, "Biomethanation Plant Assessment Based On Reliability Impact On Operational Effectiveness", Renewable Energy, Vol. 101, pp. 301-310, 2017.

[11] S. Ghosh, D. Ghosh, and D. K. Mohanta, "Impact Assessment Of Reliability Of Phasor Measurement Unit On Situational Awareness Using Generalized Stochastic Petri Nets", International Journal of Electrical Power and Energy Systems, Vol. 93, pp. 75-83, 2017.

[12] W. Gang, S. Wang, G. Augenbroe, and F. Xiao, "Robust Optimal Design Of District Cooling Systems And The Impacts Of Uncertainty And Reliability", Energy and Buildings, Vol. 122, pp. 11-22, 2016.

[13] Z. Wang and P. Wang, "A Double-Loop Adaptive Sampling Approach For SensitivityFree Dynamic Reliability Analysis", Reliability Engineering and System Safety, Vol. 142, pp. 346-356, 2015.

[14] Y. Peng, Y. Wang, Y. Y. Zi, K. -L. Tsui, and C. Zhang, "Dynamic Reliability Assessment And Prediction For Repairable Systems With Interval-Censored Data", Reliability Engineering and System Safety, Vol. 159, pp. 301-309, 2017.

[15] J. Liu and E. Zio, "System Dynamic Reliability Assessment And Failure Prognostics", Reliability Engineering and System Safety, Vol. 160, pp. 21-36, 2017.

[16] G. Levitin and A. Lisnianski, "A New Approach To Solving Problems Of Multi-State System Reliability Optimization", Quality and Reliability Engineering International, Vol. 17, No. 2, pp. 93-104, 2001.

[17] G. Levitin, Y. Dai, M. Xie, and K. L. Poh, "Optimizing Survivability Of Multi-State Systems With Multi-Level Protection By Multi-Processor Genetic Algorithm", Reliability Engineering and System Safety, Vol. 82, No. 1, pp. 93-104, 2003.

[18] H. A. Taboada, J. F. Espiritu, and D. W. Coit, "MOMS-GA: A Multi-Objective Multi-State Genetic Algorithm for System Reliability Optimization Design Problems", IEEE Transactions on Reliability, Vol. 57, No. 1, pp. 182 - 191, 2008.

[19] P. S. Shelokar, V. K. Jayaraman, and B. D. Kulkarni, "Ant Algorithm For Single And Multi-Objective Reliability Optimization Problems", Quality and Reliability engineering 
international, Vol. 18, No. 6, pp. 497-514, 2002.

[20] R. Meziane, Y. Massim, A. Zeblah, A. Ghoraf, and R. Rahli, "Reliability Optimization Using Ant Colony Algorithm Under Performance And Cost Constraints", Electric Power Systems Research, Vol. 76, No. 1-3, pp. 1-8, 2005.

[21] H. Garg and S. P. Sharma, "Multi-Objective Reliability-Redundancy Allocation Problem Using Particle Swarm Optimization", Computers \& Industrial Engineering, Vol. 64, No. 1, pp. 247-255, 2003.

[22] C. Zhang, K. Zhou, S. Yang, and Z. Shao, "On Electricity Consumption And Economic Growth In China", Renewable and Sustainable Energy Reviews, Vol. 76, pp. 353-368, 2017.

[23] K. Helin, A. Käki, B. Zakeri, R. Lahdelma, and S. Syri, "Economic Potential Of Industrial Demand Side Management In Pulp And Paper Industry", Energy, Vol. 141, pp. 1681-1694, 2017.

[24] T. Bakirtas and A. G. Akpolat, "The Relationship Between Energy Consumption, Urbanization, And Economic Growth In New Emerging-Market Countries", Energy, Vol. 147, pp. 110-121, 2018.

[25] S. Roy, "The Maximum Likelihood Optima For An Economic Load Dispatch In Presence Of Demand And Generation Variability", Energy, Vol. 147, pp. 915-923, 2018.

[26] C. E. Ebeling, An Introduction to Reliability and Maintainability Engineering, McGrawHill, Boston, 2004.

[27] P. O'Connor and A. Kleyner, Practical Reliability Engineering, 5th ed., United Kondom: John Wiley and Sons, 2012.

[28] Y. F. Wang, B. Li, T. Qin, and B. Zhang, "Probability Prediction And Cost Benefit Analysis Based On System Dynamics", Process Safety and Environmental Protection, Vol. 114, pp. 271-278, 2018.

[29] J. Forrester, Urban Dynamics, Cambridge: MIT Press, 1969.

[30] J. D. Sterman, Business Dynamics: Systems Thinking and Modeling for a Complex World, Boston: McGraw-Hill Higher Education, 2000.

[31] C. Y. Lam, S. L. Chan, and W. H. Ip, "A Structural Reliability Business Process Modelling With System Dynamics Simulation. Modeling Simulation And Optimization-Focus on App", Modeling Simulation and Optimization-Focus on Application, Vol. DOI:
10.5772/8970, pp. 259-268, 2010.

[32] E. Suryani, S. -Y. Chou, and C. -H. Chen, “Air Passenger Demand Forecasting And Passenger Terminal Capacity Expansion: A System Dynamics Framework", Expert Systems with Applications, Vol. 37, pp. 2324-2339, 2010.

[33] W. -C. Yeh and T. -C. Chu, "A Novel MultiDistribution Multi-State Flow Network and Its Reliability Optimization Problem", Reliability Engineering and System Safety, vol. 176, pp. 209-217, 2018.

[34] P. Wang, Reliability Cost/Worth Considerations in Distribution System Evaluation, Canada: Department of Electrical Engineering-University of Saskatchewan, 1998.

[35] R. Karki and R. Billinton, "Reliability/Cost Implications of PV and Wind Energy Utilization in Small Isolated Power Systems", IEEE Transactions on Energy Conversion, Vol. 16, No. 4, pp. 368 - 373, 2001.

[36] S. Elsawah, S. A. Pierce, S. H. Hamilton, and H. v. Delden, "An Overview of The System Dynamics Process For Integrated Modelling Of Socio-Ecological Systems: Lessons on Good Modelling Practice From Five Case Studies", Environmental Modelling and Software, Vol. 93, pp. 127-145, 2017.

[37] G. Qiaolun and G. Tiegang, "Profits Management For Reverse Supply Cchain With Supply Disruption", International Journal of Intelligent Engineering and Systems, Vol. 6, No. 1, pp. 1-9, 2013. 